\title{
La expresividad métrica en el Ulises dantesco
}

María CARRILlo

Universidad Nacional Autónoma de México

\section{La figura del Ulises dantesco}

En la octava Bolgia (Inf., XXVI, vv. 90-142), destinada al castigo de los consejeros fraudulentos, Dante delineará en sólo cincuenta y dos versos la figura y la historia de uno de los personajes más fascinantes de La divina commedia: Ulises y su último viaje. Son versos que figuran entre los más famosos de toda la literatura italiana, sobre los que se han detenido los críticos y exégetas durante siete siglos:

Lo maggior corno de la fiamma antica cominciò a crollarsi mormorando pur come quella cui vento affatica; indi la cima qua e là menando, come fosse la lingua che parlasse, gittò voce di fuori, e disse: "Quando mi diparti' da Circe, che sottrasse me più d'un anno là presso a Gaeta, prima che sì Enea la nomasse, né dolcezza di figlio, né la pieta del vecchio padre, né 'l debito amore lo qual dovea Penelopè far lieta, vincer poter dentro da me l'ardore ch'i' ebbi a divenir del mondo esperto, e de li vizi umani e del valore; ma misi me per l'alto mare aperto sol con un legno e con quella compagna picciola da la qual non fui diserto. L'un lito e l'altro vidi infin la Spagna, fin nel Morrocco, e l'isola de' Sardi, 
e l'altre che quel mare intorno bagna. Io e' compagni eravam vecchi e tardi quando venimmo a quella foce stretta dov'Ercule segnò li suoi riguardi, acciò che l'uom più oltre non si metta: da la man destra mi lasciai Sibilia, da l'altra già m'avea lasciata Setta. ' $O$ frati,' dissi 'che per cento milia perigli siete giunti a l'occidente, a questa tanto picciola vigilia de' nostri sensi ch'è del rimanente, non vogliate negar l'esperïenza, di retro al sol, del mondo sanza gente.

Considerate la vostra semenza: fatti non foste a viver come bruti, ma per seguir virtute e canoscenza.'

Li miei compagni fec'io sì aguti, con questa orazion picciola, al cammino, che a pena poscia li avrei ritenuti; e volta nostra poppa nel mattino, dei remi facemmo ali al folle volo, sempre acquistando dal lato mancino.

Tutte le stelle già dell'altro polo vedea la notte, e 'l nostro tanto basso, che non surgea fuor del marin suolo.

Cinque volte racceso e tante casso lo lume era di sotto dalla luna, poi che 'ntrati eravam ne l'alto passo, quando n'apparve una montagna, bruna per la distanza, e parvemi alta tanto quanto veduta non avea alcuna.

Noi ci allegrammo, e tosto tornò in pianto; ché de la nova terra un turbo nacque, e percosse del legno il primo canto.

Tre volte il fè girar con tutte l'acque:

alla quarta levar la poppa in suso e la prora ire in giù, com'altrui piacque, infin che 'l mar fu sovra noi richiuso". (Alighieri, 1949)'

${ }^{1}$ Todas las citas provienen de la edición de Scartazzini-Vandelli; en lo sucesivo sólo se mencionará el número de los versos citados. 
Cierto es que Ulises, junto con Diomedes, aparece condenado en la bolgia de los consejeros fraudulentos por los engaños cometidos durante la guerra de Troya, pero su historia, presentada hacia el final del canto, no tiene relación alguna con el pecado que condicionó su suerte eterna. Por el contrario, en esta historia el ambiente infernal se desvanece para dar paso a uno de los más altos ideales de la Commedia: la capacidad de pensamiento y la inclinación natural hacia la búsqueda del conocimiento como cualidades inherentes al ser humano.

Cabe mencionar que en la época de Dante la Odisea era desconocida. La figura de Ulises apenas se esbozaba a través de algunas leyendas en las que se omitía el regreso del héroe a Ítaca o se hablaba de la realización de un segundo viaje. De ahí que Dante otorgue un significado propio a este héroe del ejército griego y haga de Ulises la encarnación del deseo insaciable de conocimiento.

Es el mismo Ulises quien narra su historia. Él nos cuenta cómo en su último viaje, después de haber recorrido el mundo conocido, se dirige hacia el hemisferio terrestre desconocido emprendiendo una peligrosa aventura motivada por el ansia de sabiduría que lo había vencido. Aunque él está consciente del riesgo que corre al navegar hacia donde no encontrará puertos y seguramente morirá, no quiere quedarse sin conocer cómo es el otro lado de la tierra, el mundo "sin gente”. Y es que además esta decisión no hace sino obedecer las leyes humanas, pues Ulises logra que sus compañeros de viaje emprendan el camino hacia lo desconocido recordándoles que el hombre fue creado para pensar, no para vivir como una bestia:

Considerate la vostra semenza:

fatti non foste a viver come bruti, ma per seguir virtute e canoscenza. (118-120)

Ulises y sus compañeros navegan durante cinco meses hasta que en las antípodas de Jerusalén se encuentran con la montaña del paraíso terrestre, pero, antes de que pudieran sacar provecho del gran descubrimiento, su barco es hundido por voluntad divina.

\section{Las interpretaciones del último viaje de Ulises}

El viaje y el naufragio de Ulises han desencadenado numerosas interpretaciones. Al naufragio se le ha visto como un castigo divino ante la desobediencia de Ulises que no debía intentar traspasar las columnas de Hércules, por lo que también se habla de la existencia de una prohibición divina hacia el camino del conocimiento. Y por otro lado el arriesgado viaje le ha granjeado a Ulises el 
nombramiento de precursor del espíritu del hombre renacentista que viajando se encontrará con el Nuevo Mundo.

Todas éstas son ideas que dificilmente encuentran apoyo en el texto y esto se demuestra claramente en el estudio de Mario Fubini, "Il peccato di Ulisse" (Fubini, 1966), y en el de Mariapia Lamberti, "Algo más sobre el Ulises dantesco (reflexiones sobre una interpretación alegórica)" (Lamberti, 1997). En estos dos artículos se desmontan las interpretaciones del último viaje de Ulises que alrededor de la poesía de Dante han construido, como señala Fubini, "un fastidioso edificio de fantasie e congetture" (Fubini, 1966: 1); y al mismo tiempo tanto Mario Fubini como Mariapia Lamberti proponen una lectura de este episodio comprobable en los versos mismos.

De este modo, en los dos estudios se recuerda insistentemente que el último viaje de Ulises no es la causa de su condenación eterna, por lo que el naufragio tampoco es un castigo divino. ${ }^{2}$ Ulises no hace sino obedecer el deseo de conocimiento que en sí mismo no es pecaminoso; tan es así que Ulises es guiado por la Virtud aun después de traspasar las columnas de Hércules que además no representan una prohibición, sino una advertencia que indica a los hombres que a partir de ese punto la navegación ya no es segura. Sin embargo, Ulises ya no puede llegar al paraíso terrestre y porque, como todos los sabios que existieron antes de la Revelación, carecía de la gracia divina y su camino intelectual no podía llegar a su fin último: la bienaventuranza. Por ello Fubini y Mariapia Lamberti coinciden al afirmar que el naufragio de Ulises, lejos de ser un castigo o una venganza, es una medida para impedir que se violaran las leyes divinas. Ulises, sin la guía de la sabiduría divina, simplemente no estaba preparado para alcanzar el paraíso terrestre:

Es un viaje que lo lleva al supremo triunfo de vislumbrar aquella misma Verdad que desconoce y que no está preparado para conocer. Su muerte fatal y desoladora no es castigo, sino la lógica consecuencia de esta falta de preparación [...]. Pero esta muerte inevitable no cancela la ejemplaridad de su empresa ni su valor didascálico, ni la exaltación de la noble obediencia a los dictámenes de la naturaleza humana, y por ende de Dios. (Lamberti, 1997: 59)

2Esta opinión es compartida por Auerbach en "Dante poeta del mondo terreno" (Auerbach, 1974: 136), donde señala que Ulises fue condenado por la traición contra Troya, pero el recuerdo que se fija en el lector es el de la natural inclinación hacia la sabiduría presente en este personaje. Quizá por ello se considere el viaje hacia lo desconocido como la acción que determinó la suerte eterna de Ulises. 
En gran medida, la lectura propuesta por Fubini y Lamberti resulta tan convincente porque no analiza el relato de Ulises como un elemento aislado, sino que lo pone en relación con el pensamiento de Dante y sobre todo con la entera fisonomía de La divina commedia. Sin embargo, ahora intentaremos seguir otro método de análisis que permitirá obtener una interpretación del episodio de Ulises a partir de uno de los principios teóricos más importantes de la corriente estilística: la relación indisoluble entre los rasgos formales y el contenido ideológico del texto.

El mismo Fubini, uno de los mayores exponentes de la estilistica, expone este principio en su famoso ensayo Métrica y poesia, un estudio dedicado a la identificación de los fenómenos métricos que en poesía construyen el ritmo, considerado como el arte mismo de la expresión poética: pues el ritmo posee un valor expresivo que no sólo se encuentra en relación directa con el contenido, sino que también es a su vez portador de significado.

De este modo, en Métrica y poesía, así como en otros estudios de crítica estilística, se plantea la necesidad de un acercamiento profundo al ritmo poético de La divina commedia. ${ }^{3} \mathrm{Y}$ es ésta la propuesta que seguiremos para el análisis de los cincuenta y dos versos que componen el discurso de Ulises. Tomaremos en cuenta fenómenos métricos como las cesuras, las sinalefas, los encabalgamientos, la disposición sintáctica y el esquema acentual formado por el acento natural de las palabras. No está por demás mencionar que no tomaremos en consideración ningún modelo abstracto del endecasilabo; partiremos sólo de la idea de que el poeta tiene once sílabas con un acento fijo en décima para insertar la materia poética. Haremos una lectura progresiva, analizaremos un terceto a la vez, dado que casi todos son tercetos sintácticamente cerrados, y cuando la frase se prolongue en más de un terceto lo haremos notar.

\section{El discurso de Ulises, recursos métricos y contenido ideológico}

Antes de comenzar el análisis del discurso de Ulises hay que recordar algunos antecedentes que envuelven a esta historia en un halo de solemnidad y de misterio. Desde el momento en que Dante ve la llama que cubre a Ulises y a Diomedes, ruega a su maestro con desmedida insistencia que haga acercarse

${ }^{3}$ Sobre la importancia de acercarse al ritmo poético de La divina commedia, vid. los estudios de estilística dedicados al poema sacro de Helmut Hatzfeld (1975: 94-97). También es importante el estudio sobre el ritmo poético y la caracterización de los personajes de E. Auerbach, que toma en consideración a Farinata y Cavalcanti (Auerbach, 1950: 166-193). 
a uno de ellos. Virgilio ya le ha contado la acciones que los han condenado, pero esto a Dante no le interesa, él quiere saber algo más. Este deseo es entendido inmediatamente por Virgilio y él mismo se dirige a las dos almas con la solemnidad debida. Será hasta el último verso del discurso de Virgilio cuando se revelará al lector la historia que Dante desea que sea contada: "dove per lui perduto a morir gissi" (v. 84). Vemos entonces cómo ya desde los preliminares del discurso de Ulises se desencadena una tensión poética que será magistralmente sostenida a lo largo de todo el relato.

Esto lo notamos desde la primera palabra del discurso de Ulises, que queda suspendida en el final del terceto anterior: Quando. Pero además esta primera frase se desborda también del verso siguiente con un marcado encabalgamiento sottrasse // me. Así, en el primer terceto, aunque sólo se estén proporcionando referencias históricas junto con una ubicación temporal, los versos se agolpan y se crea cierta vivạcidad en el ritmo poético mediante la disposición sintáctica, aunque el esquema acentual guarda gran simetria:

gittò voce di fuori, e disse: "Quando

mi diparti' da Circe, che sottrasse

me più d'un anno là presso a Gaeta,

prima che sì Enea la nomasse, (vv. 90-93)
$2-3-6-8-10$

4-6-10

$1-4-6-10$

$1-4-6-10$

El primer verso, con cinco acentos, inicia con dos acentos contiguos sobre la misma vocal "o", y nos transmite así la sensación del grito, del esfuerzo vocal inicial. Luego inicia la serie de versos con la misma acentuación. Vemos además que se conserva un particular equilibrio en los últimos dos versos, donde ya no se presenta encabalgamiento, pero sí un acento en primera posición, lo que renueva el ritmo y sostiene la tensión poética.

Esto se prolonga en el terceto siguiente, dedicado a tres negaciones, donde el ritmo se modifica mediante el esquema acentual que ahora es principalmente asimétrico, con fuertes cesuras. Sólo hasta el último verso el ritmo se relaja, pues se pierden dos acentos y la cesura desaparece:

né dolcezza di figlio, né la pièta

del vecchio padre, né 'l debito amore

lo qual dovea Penelopè far lieta, (vv. 94-96)
$1-3-6-/ 8-10$

$2-4-/ 6-7-10$

$4-8-10$

Aquí aparecen tres afectos familiares, pero precedidos por una negación, lo que sugiere la presencia de algo más fuerte que éstos. La explicación se dará hasta el terceto siguiente con el valor llamativo de un acento en la. en el verbo vincer. Para que ésta sea la primera palabra del verso es necesario alterar el 
orden sintáctico y posponer el verbo poter, lo que revela la especial importancia de esta palabra. Pues los afectos familiares, puestos en una lucha interna, son vencidos por un deseo más fuerte, representado como fuego, l'ardore, que es el anhelo de conocimiento:

Vincer poter dentro da me l'ardore ch'io ebbi a divenir del mondo esperto

e delli vizi umani e del valore; (vv. 97-99)
$1-4 / 5-8-10$

$2-6 / 8-10$

$4-6-10$

Como observamos en este terceto el ritmo se crea principalmente a través de la cesura que paulatinamente desaparece. En el primer verso la pausa es marcadísima después de vincer poter con un acento contiguo en la siguiente palabra, dentro. En el verso siguiente aún podría hacerse una pausa después de divenir. Pero en el último verso con la repetición de la conjunción copulativa $e$, que crea una sinalefa, la cesura desaparece, pues, si la sinalefa se rompe, se altera la medida del verso. Además estas conjunciones se unen con el hemistiquio del verso anterior, del mondo esperto // e delli..., lo que nos hace pensar que en el camino de la superación intelectual es indispensable el conocimiento tanto de los valores, como de los vicios humanos.

En el terceto siguiente aparece el resultado del deseo incontenible que ha vencido a Ulises: la decisión de emprender un nuevo viaje para así intentar saciar su anhelo de conocimiento. En el primer verso, dedicado al comienzo de esta aventura, el ritmo se acelera y así corresponde con la acción representada: navegar en mar abierto. Aparecen cinco acentos que además contrastan con el verso anterior que tenía sólo tres. No obstante, estos acentos guardan entre sí una disposición simétrica: son sólo las sílabas pares las que se acentúan:

ma misi me per l'alto mare aperto (v. 100)

El resto del terceto tiene una función descriptiva que completa la información del primer verso. Se presentan las condiciones del viaje: el único barco y los compañeros que siempre le serán fieles a Ulises. Hay un encabalgamiento que obliga a prestar atención en las palabras compagna // picciola, o sea en los pocos que decidieron acompañar a Ulises en esta aventura y que comparten, como se verá más adelante, el amor por el conocimiento:

sol con un legno e con quella compagna

picciola dalla qual non fui diserto. (vv. 101-102) 
La estructura ritmica es similar en el terceto siguiente, donde se describe la trayectoria del viaje de Ulises mediante referencias geográficas. El verbo que indica la acción principal, vidi, que es además uno de los principios del conocimiento, es colocado a la mitad del primer verso y el ritmo se acelera con la acentuación de las solas sílabas pares. De igual manera, los dos versos siguientes serán una extensión explicativa del primero. Sólo que ahora en el último verso se agregará un acento:
L'un lito e l'altro vidi infin la Spagna, 2-4-6-8-10 fin nel Morocco, e l'isola de' Sardi, e l'altre che quel mare intorno bagna. (vv. 103-105)
2-6-8-10

El primer verso del terceto siguiente está dedicado al estado físico de Ulises y sus compañeros que ya son viejos y lentos. Estas palabras son destacadas por la marcada cesura, provocada por acentos contiguos en 7a. y 8a., que las precede. Podemos pensar entonces que en la aventura hacia la búsqueda del conocimiento la fuerza física no es indispensable, pero sí la fuerza intelectual que obedece a un proceso necesariamente apoyado en la madurez y la experiencia:

lo e' compagni eravam vecchi e tardi (v. 106)

$1-4-7 / 8-10$

Los dos versos siguientes cuentan la llegada al final del mundo conocido cuyo límite es señalado por las columnas de Hércules. De nuevo el ritmo se acelera. En el segundo verso, donde se encuentra el verbo, venimmo, aparecen cuatro acentos (y uno menor) dispuestos de manera armónica. En el verso siguiente, donde se hace mención a Hércules, sólo aparecen tres acentos (y uno menor) y esto, como ya hemos visto en las estructuras rítmicas anteriores, tiene un valor meramente descriptivo, por lo que suponemos que las columnas de Hércules son simplemente una referencia geográfica, no una prohibición divina:

quando venimmo a quella foce stretta $1-4-[6]-8-10$ dov'Ercule segnò li suoi riguardi, (vv. 107-108) $2-6-[8]-10$

La unidad sintáctica de este terceto se prolonga hasta el primer verso del siguiente, también con una disposición acentual simétrica:

acciò che l'uom più oltre non si metta: (v. 109) 
Sin embargo, este verso, donde se presenta la advertencia para el hombre, no es el que más destaca en el terceto; son más importantes los dos versos siguientes en los que el ritmo poético se altera:

dalla man destra mi lasciai Sibilia,

dall'altra già m'avea lasciata Setta. (vv. 110-111)

2-4-6-8-10

En el segundo verso aparece un acento en 3a. que ha aparecido sólo una vez en el verso 94, pero además este acento es seguido por otro en 4a., y asimismo en el tercer verso aparecen acentuadas todas las sílabas pares. La alteración del ritmo poético en estos versos, donde Ulises reconoce que ya ha recorrido todo el mundo conocido, nos sugiere el ansia incontenible de Ulises por continuar el camino hacia lo desconocido.

La desesperación de Ulises es evidente, pero para continuar su viaje primero necesita convencer a sus compañeros, por lo que los tres tercetos siguientes están dedicados al pequeño discurso (orazion picciola) con el que logra persuadirlos.

El primer verso comienza directamente con la invocación, $O$ frati, seguida del verbo dissi, así sabemos que se trata de las palabras de Ulises hacia sus compañeros. Él los llama de manera afectiva, frati, y les recuerda hiperbólicamente, cento milia perigli, los peligros que heroicamente han sorteado para llegar hasta ese punto. Después los exhorta a aprovechar el poco de vida que les resta, y ahora Ulises se incluye entre ellos, para conocer algo más: el mundo detrás del sol, el mundo sin gente, o sea el mundo de lo desconocido.

Estos razonamientos ocupan los primeros seis versos en los que aparecen interesantes juegos rítmicos provocados por variaciones de la disposición sintáctica y acentual:

'O frati' dissi, 'che per cento milia perigli siete giunti all'occidente, a questa tanto picciola vigilia de' nostri sensi ch'è del rimanente, non vogliate negar l'esperïenza, di retro al sol, del mondo sanza gente. (vv. 112-117)
2-4-8-10

2-4-6-10

2-4-6-10

2-4-6-10

$3-/-6-10$

$2-4 /-6-8-10$

En el primer verso aparecen cuatro acentos en silabas pares. En los tres siguientes el acento de 8a. se desplaza a 6a. y este esquema con acentos en 2a., 4a., 6a. y 10a. se sigue con una rigidez absoluta. No obstante, las unidades sintácticas se prolongan irregularmente entre un verso y otro, por lo que aparecen dos encabalgamientos: cento milia // perigli... y picciola vigilia // de' nostri sensi... 
En los dos versos siguientes ahora la cesura será el elemento constante y el esquema acentual el variable. Primero aparecen acentos en 3a., 6a. y 10a. Después aparece la acentuación de todas las sílabas pares, que como ya hemos visto, es el ritmo acostumbrado para destacar un verso.

Esta armónica irregularidad del ritmo poético compuesta por un elemento constante y otro variante, es vista por Fubini como una representación de la familiaridad con la que Ulises se dirige a sus compañeros (Fubini, 1969: 58-60). Cierto. Pero además esta variabilidad del ritmo permite que destaque enormemente la solemnidad del último terceto:

Considerate la vostra semenza:

$4-/-7-10$

fatti non foste a viver come bruti, $1-4-/-6-10$ ma per seguir virtute e canoscenza.' (vv. 118-120)

$4 /-6-10$

Estos versos son poseedores de una sentencia que inmediatamente se fija en la memoria gracias a la regularidad del ritmo poético. Los versos tienen pocos acentos y esto relaja el discurso, pero al mismo tiempo lo vuelve solemne. Los tres versos son endecasílabos a minore con acento dominante en 4a. Pero veamos las palabras que quedan después de la cesura. En el primer verso destaca vostra semenza, la invitación a reflexionar sobre la naturaleza humana. En el segundo verso destaca viver come bruti, pero precedido por una negación, fatti non foste, de ahi que este verso sea el único del terceto con acento en 1a., así la atención se distribuye en el verso entero, donde se recuerda que el hombre no fue creado para vivir como una bestia. Finalmente, en el último verso se presenta la inclinación propia de todo hombre y aquí destacan las palabras que aparecen después de la cesura, virtute e canoscenza.

Así, apoyado en el ritmo poético el discurso persuasivo de Ulises defiende un alto ideal humano: la capacidad de pensamiento y la inclinación natural hacia la búsqueda del conocimiento como cualidades propias de la naturaleza humana.

En el terceto siguiente vemos el poder persuasivo de este discurso en la reacción de los compañeros de Ulises:

$\begin{array}{ll}\text { Li miei compagni fec'io si aguti, } & 2-4-7-8-10 \\ \text { con questa orazion picciola, al cammino, } & 2-5-6-10 \\ \text { che a pena poscia li avrei ritenuti; (vv. 121-123) } & 2-4-7-10\end{array}$

Pero aquí, además de los acentos contiguos sobre la misma vocal "i", que hacen sobresalir en el primer verso las palabras fec 'io si aguti y en el segundo verso las palabras orazion picciola, no aparece ningún otro fenómeno expre- 
sivo relevante. El ritmo poético toma por ahora un pequeño reposo, pues en el siguiente terceto se producirá una variante rítmica única en todo el discurso:

E volta nostra poppa nel mattino, dei remi facemmo ali al folle volo, sempre acquistando dal lato mancino. (vv. 124-126)
2-4-6-10

$2-5-6-8-10$

$1-4-7-10$

Ulises y sus compañeros han decidido seguir el camino hacia lo desconocido. En el primer verso aparece la preparación para el viaje con acentuación en las sílabas pares. En el segundo aparece el folle volo con el que se da inicio al viaje, una acción guiada por los remos del barco, o sea por la voluntad humana. Este verso tiene cinco acentos pero ahora sin una disposición armónica: aparecen acentos contiguos en 5a. y 6a., hay que recordar que el acento en 5a. había aparecido sólo una vez en el segundo verso del terceto anterior. La irregularidad rítmica nos permite comprobar la insensatez de la decisión de Ulises. Y esto es aún más evidente si recordamos el verso 100 , cuando comienza el viaje, $m a$ misi me..., un verso en el que sí se acelera el ritmo poético, pero se conserva una disposición acentual simétrica. Hay que notar que en estos dos tercetos el verso final presenta la acentuación de 4a. y 7a., muy aceptable en el endecasílabo italiano, pero que destaca con su ritmo inusual, y que Dante usa para subrayar pasajes significativos.

El viaje es llamado folle volo porque Ulises decide seguir una peligrosa aventura sin prestar atención a la advertencia de las columnas de Hércules, más allá de las cuales ya no se encontrarán apoyos a la navegación. Sin embargo, no se trata de una prohibición divina, tan es así que después de este punto Ulises y sus compañeros navegan durante cinco meses sin mayores contratiempos, como también lo demuestra el ritmo poético de los dos tercetos siguientes.

En el primero se proporciona una referencia geográfica mediante la contemplación de la bóveda celeste. El esquema acentual comienza con cuatro acentos en sílabas pares y un acento en la. que tiene un valor llamativo. En el segundo verso el primer acento se desplaza a 2a. El último verso pierde un acento, por lo que el primer acento aparece en $4 a$., lo que le da un valor conclusivo; el ritmo ya no es del de 4a. y $7 \mathrm{a}$., pero la irregularidad que marca la cadencia final aparece con los acentos contiguos de $9 \mathrm{a}$. y 10a.:

Tutte le stelle già dell'altro polo vedea la notte, e 'l nostro tanto basso, che non surgea fuor del marin suolo. (vv. 127-129)
$1-4-6-8-10$

2-4-6-8-10

4-6-9-10 
El terceto siguiente está dedicado al tiempo trascurrido durante el viaje, mediante referencias al ciclo lunar. El ritmo poético es similar al del terceto anterior, sólo que ahora la cadencia se manifiesta porque en el primer verso aparecen cinco acentos, en 1a., 3a., 6a., 8a. y 10a., y el primer acento paulatinamente se desplaza hacia adelante. En el último verso se añade el acento en 8a. posición, eliminado en el segundo verso, para un mayor efecto de cadencia conclusiva:

Cinque volte racceso e tante casso

lo lume era di sotto dalla luna, $1-3-6-8-10$

poi che 'ntrati eravam nell'alto passo, (vv. 130-132)

$2-3-6-10$

$3-6-8-10$

La frase se prolonga al siguiente terceto que comienza con la palabra quando con la que advertimos la presencia de un acontecimiento que rompe con la armonía del viaje. El acontecimiento es la aparición de la montaña del paraíso terrestre. La montaña aparece oscura y esta oscuridad destaca por el encabalgamiento bruna $/ /$ per la distanza. En un sentido literal la montaña se percibe oscura porque es divisada desde lejos, pero también podemos pensar en la oscuridad como la representación de la falta de entendimiento, pues Ulises - representante simbólico de la humanidad anterior a la Revelación- - no estaba preparado para acercarse a ella: la sabiduria humana no le bastaba, necesitaba la guía de la sabiduría divina:

quando n'apparve una montagna, bruna per la distanza, e parvemi alta tanto quanto veduta non avea alcuna. (vv. 133-135)

\section{1-4-8-10}

4-6-8-10

$1-4-6-10$

El ritmo poético no se desacelera hacia el final del terceto, como sucedía en los anteriores. Ahora vemos cómo los acentos se agolpan desde el segundo hemistiquio del segundo verso (cuyos acentos recaen todos en la vocal "a", como un eco de la exclamación de maravilla) y además el tercer verso, en contraste con los últimos versos de los tercetos anteriores, tiene acento en la., lo que sugiere la emoción de Ulises ante su gran descubrimiento. Emoción y pesadumbre, como lo sugieren las vocales acentuadas, que se alternan únicamente entre la "a", la más abierta, y la "u", la más oscura.

En el siguiente terceto el primer verso, sintácticamente cerrado, está dedicado a las emociones de Ulises y sus compañeros al divisar la montaña: una alegría que inmediatamente se convierte en llanto. La primera parte del verso está ocupada por el verbo allegrammo, y la segunda por la transformación de la alegría en llanto, tornò in pianto, dos palabras que sobresalen por la presencia de acentos contiguos, aunque son acentos mediados por la distensión vocálica de una sinalefa: 
Noi ci allegrammo, e tosto tornò in pianto; (v. 136) $\quad 1-4-6-9-10$

Los dos versos siguientes explican la razón del llanto: un remolino que arrastra el barco. Sin embargo, en esta representación de la catástrofe no hay una disposición acentual o sintáctica que pudiera marcar una escena trágica. El primer verso conserva una disposición acentual simétrica y el último, con el primer acento en 3a. y la pérdida del acento en $4 \mathrm{a}$., tiene un valor conclusivo:
chè della nova terra un turbo nacque, $1-4-6-8-10$
e percosse del legno il primo canto. (vv. 136-138)
3-6-8-10

Y este ritmo poético se conserva en el siguiente terceto, el último. El primer verso es acentuado en todas las sílabas pares, por lo que el ritmo se acelera (y puede reconocerse un acento en primera posición, llevando el número de los acentos a seis, un ritmo velocísimo) y se sugiere el movimiento del barco. El verso siguiente pierde un acento, mientras que el último, dedicado al hundimiento del barco por voluntad divina, conserva los cuatro acentos, pero las palabras que ocupan el segundo hemistiquio, altrui piacque, sobresalen por los acentos contiguos, ahora sin la distensión vocálica de una sinalefa como veíamos en el verso 136. La presencia de la voluntad divina queda rítmicamente mucho más destacada que la representación de la catástrofe, lo que nos hace pensar que el naufragio, lejos de ser un castigo divino, es una consecuencia lógica del folle volo de Ulises:

Tre volte il fè girar con tutte l'acque:

alla quarta levar la poppa in suso

[1]-2-4-6-8-10

e la prora ire in giù, com'altrui piacque, (vv. 139-141) 3-6-9-10

Finalmente, en el verso que cierra la historia de Ulises:
infin che 'l mar fu sopra noi richiuso. (v. 142)
2-4-6-8-10

La disposición acentual simétrica, el número máximo de acentos y la alternancia de cuatro vocales progresivamente más oscuras ("i-a-o-u") tienen un valor altamente conclusivo. Con esta armonía se resuelve la tensión poética, pues la pregunta de Dante y Virgilio ha sido contestada. Pero además este ritmo poético, que vuelve a ser armónico, sugiere el restablecimiento del orden que estaba a punto de ser alterado por la llegada de Ulises a la montaña del paraíso terrestre.

Observar el valor expresivo de la métrica en la representación del Ulises dantesco permite apreciar cómo la tensión poética es admirablemente sostenida 
mediante una renovación constante del ritmo. Pero además en estos versos el ritmo poético también es expresión del contenido ideológico y no puede observarse de manera abstracta. Tan es así que a partir del análisis de los recursos métricos podemos comprobar la interpretación de Mario Fubini y Mariapia Lamberti y por tanto afirmar que no existe en el episodio de Ulises ninguna prohibición divina para adentrarse en el camino del conocimiento. El hombre sí puede llegar al paraíso terrestre, pero guiado por la gracia divina y después de atravesar un proceso de purificación espiritual.

De cualquier manera, compartamos o no el pensamiento de Dante, no podemos dejar de lado la importante lección humana que encierran estos versos. Pues la historia del último viaje de Ulises bien puede ser leída como una invitación para correr la aventura de internarse en un fascinante proceso de superación intelectual, sin olvidar que las facultades necesarias ya están presentes en la naturaleza humana.

\section{Bibliografia}

AlIGHIERI, Dante. 2000 [1949]. La divina commedia. Con il commento scartazziniano rifatto da Giuseppe Vandelli. Milán: Hoepli.

AUERBACH, Erich. 1974. "Dante poeta del mondo terreno". Studi su Dante.

Trad. Maria Luisa DE Pieri Binino. Milán: Feltrinelli. 3-169. . 1950. "Farinata y Cavalcante". Mimesis. La representación de la realidad en la literatura occidental. México: FCE. 166-193.

FuBINI, Mario. 1969. Métrica y poesía. Trad. Milagros Arizmendi y María Hernández Esteban. Barcelona: Planeta.

. 1966. "Il peccato di Ulisse". Il peccato di Ulisse e altri scritti danteschi. Milán / Nápoles: Ricciardi. 1-36.

HATZFELD, Helmut. 1975. "La divina commedia". Estudios de estilistica. Barcelona: Planeta. 94-97.

LAMBERTI, Mariapia. 1997. "Algo más sobre el Ulises dantesco (reflexiones sobre una interpretación alegórica)". Ed. M. LAMBERTI y Franca BIzZONI. Palabras, poetas e imágenes de Italia. Actas de las II Jornadas de Estudios Italianos. México: Cátedra Extraordinaria Italo Calvino, Facultad de Filosofia y Letras, UNAM. 45-61. 